\section{GHPSS multicenter Italian survey: smoking prevalence, knowledge and attitudes, and tobacco cessation training among third-year medical students}

\author{
Rosella Saulle1, Claudio Bontempi' ${ }^{1}$ Vincenzo Baldo², Giovanni Boccia³ \\ Guglielmo Bonaccorsi ${ }^{4}$, Silvio Brusaferro ${ }^{5}$, Francesco Donato ${ }^{6}$, \\ Alberto Firenze 7 , Pasquale Gregorio ${ }^{8}$, Gabriele Pelissero ${ }^{9}$, Alberto Sella ${ }^{10}$, \\ Roberta Siliquini ${ }^{11}$, Antonio Boccia', and Giuseppe La Torre ${ }^{1,12}$ \\ ${ }^{1}$ Department of Public Health and Infectious Diseases, Sapienza University, Rome; ${ }^{2}$ Department of \\ Environmental and Public Health, University of Padua, Padua; ${ }^{3}$ Chair of Hygiene, University of \\ Salerno, Fisciano; ${ }^{4}$ Department of Public Health, University of Florence, Florence; ${ }^{5}$ Department of \\ Pathology and Experimental and Clinical Medicine, University of Udine, Udine; ${ }^{6}$ Department of \\ Experimental and Applied Medicine, Epidemiology and Public Health, University of Brescia, Brescia; \\ ${ }^{7}$ Department of Health Promotion Science G D'Alessandro, University of Palermo, Palermo; \\ ${ }^{8}$ Department of Experimental and Applied Medicine, University of Ferrara, Ferrara; ${ }^{9}$ Department of \\ Hygiene, University of Pavia, Pavia; ${ }^{10}$ Institute of Forensic Medicine, University of Insubria, Varese; \\ ${ }^{11}$ Department of Public Health and Microbiology, Turin; ${ }^{12}$ Eleonora Lorillard Spencer-Cenci \\ Foundation, Rome, Italy
}

\section{ABSTRACT}

Aims and background. Healthcare professionals have an important role to play both as advisers - influencing smoking cessation - and as role models. The aims of this study were to examine smoking prevalence, knowledge and attitudes among Italian university students attending medical schools using the Global Health Professions Student Survey (GHPSS) approach.

Methods and study design. A multicenter cross-sectional study was conducted among University students of 9 Italian medical schools (age ranging between 19 and 29 years). The GHPSS questionnaire was self-administered. A logistic regression model was used to identify possible factors associated with tobacco smoking status. Data were analyzed with the software SPSS 19.0 for Windows.

Results. Seven hundred thirty medical students (response rate $100 \%$ ) were enrolled. The prevalence of current smokers was $20.4 \%$ (males $22.4 \%$, females $19.1 \%$ ). Of the total sample, $87.7 \%$ believed that health professionals should receive specific training in techniques to quit smoking, and $65 \%$ believed that health professionals had a role in giving advice or information about smoking cessation. However, $89.4 \%$ answered that they had not received specific training on smoking cessation techniques. Multivariate analysis showed that students belonging to universities in southern Italy were more likely to be smokers ( $\mathrm{OR}=2.00$; 95\% CI: 1.03-3.97).

Conclusions. This Italian multicenter survey found that one fifth of future medical doctors are smokers. There is a need to adopt a standard undergraduate curriculum containing comprehensive tobacco prevention and cessation training to improve their effectiveness as role models.

\section{Introduction}

Tobacco smoking is the leading cause of preventable deaths in developed as well as developing countries ${ }^{1}$. In Italy, $21.7 \%$ of the entire adult population are current smokers (over 11 million) ${ }^{2}$.

Healthcare workers play an important role in helping smokers to quit ${ }^{3,4}$ and giving them smoking cessation advice and assistance. Medical schools can be essential in pro-
Key words: smoking, tobacco use, Global Health Professions Student Survey.

Author disclosure statement: There are no competing financial interests related to this work.

Correspondence to: Giuseppe La Torre, Department of Public Health and Infectious Diseases, Sapienza University, Piazzale Aldo Moro 5, 00185 Rome, Italy.

Tel +39-06-49694309; email giuseppe.latorre@uniroma1.it

Received May 14, 2012; accepted September 10, 2012. 
viding students with knowledge about smoking-related diseases and smoking cessation training to help patients ${ }^{5-}$ ${ }^{7}$, considering that smoking-related issues should be "part of the core curriculum of the undergraduate and postgraduate education and training of physicians" (European Respiratory Task Force) $)^{8}$. Unfortunately, until now such a core curriculum has been lacking in Italian medical schools ${ }^{9,10}$, while there is evidence that introducing tobacco knowledge into the curriculum is effective in reducing the prevalence of smoking among medical students ${ }^{11}$.

Healthcare professionals have an important role to play both as advisers - influencing smoking cessation and as role models ${ }^{12,13}$. Since there is evidence that physicians in Italy are not advising smokers to quit ${ }^{14}$, healthcare professionals, and particularly physicians, should be encouraged to assist smokers to quit, especially considering that almost half of former smokers state health conditions as the main reason to stop smoking $^{15}$. But paradoxically only $20 \%$ of patients receive advice and assistance to quit, and fewer than $2 \%$ receive pharmacotherapy ${ }^{16}$. Nevertheless, quitting smoking has a great economic benefit by improving the health of the population.

Although healthcare workers acknowledge their professional responsibility as models of good health practices and know the health risks associated with smoking, many continue to smoke ${ }^{17-19}$ and in some countries the prevalence of smoking is higher among health professionals than in the general population ${ }^{20-24}$.

Healthcare workers could serve as role models for positive health behaviors and could take an active role in facilitating smoking cessation in the population, but first they must incorporate positive health behaviors into their personal lifestyle ${ }^{21-23}$. Healthcare workers who smoke downplay their role in patient education and tend to show a more negative attitude towards patients.

There is evidence that smoking cessation interventions among healthcare workers can be effective ${ }^{25}$. This is of particular interest both for reducing the tobacco smoking prevalence among these professionals and helping them to be a useful model for the general population.

\section{Methods}

\section{Study design and population}

This multicenter cross-sectional study was carried out in Italian medical schools belonging to 9 cities of northern (Turin, Padua, Florence, Brescia, Ferrara, Varese and Udine) and southern (Palermo, Salerno) Italy. The universities were randomly chosen from a list of all medical schools in Italy. The participating universities were asked to perform the survey during classes of the third year of medicine given by the dean of the university. The random sample of students was following the second semester of the third year of study (March-July 2010).
The research protocol was approved by all the local ethics committees and the Italian schools of medicine involved gave us their consent to be mentioned.

\section{The questionnaires}

The tool used in this survey was the Global Health Professions Student Survey (GHPSS) questionnaire developed by the Tobacco Free Initiative (TFI), the World Health Organization (WHO) and the Office on Smoking and Health (OSH) of the Centers for Disease Control and Prevention (CDC), in consultation with a range of countries representing the 6 WHO regions. GHPSS is an important part of the Global Tobacco Surveillance System (GTSS) that was started in 1999.

The medical students filled in the questionnaires during regular class sessions in an anonymous, voluntary manner, in accordance with the protocol developed by WHO Europe and the $\mathrm{CDC}^{25}$.

The original version of the GHPSS questionnaire was translated into Italian by expert English-Italian translators and modified by adding country-specific questions. The translated version had been tested previously ${ }^{26}$ and Cronbach's alpha calculated. The questionnaire showed excellent reliability properties in the sample and appeared to have perfect performance in terms of internal consistency and validity: Cronbach's alpha was 0.81 for the entire section VI (44 items) ${ }^{26}$.

The original questionnaire comprised 42 questions divided into 6 sections, but in the present study we used an alternative version, adding one country-specific question on knowledge about the use of antidepressants (such as bupropion) and acetylcholine receptor partial agonists (such as varenicline or Champix) and counseling techniques in tobacco cessation programs.

The questionnaire therefore consisted of 44 questions distributed over the following sections:

1. Prevalence of tobacco use (questions 1-9)

2. Exposure to environmental tobacco smoke (i.e. time spent with people who smoke in places other than home) (questions 10-13)

3. Attitudes (i.e. opinions about no-smoking policies and laws, and about the role of healthcare professionals in smoking cessation) (questions 14-24)

4. Behavior/cessation (i.e. smoking habit, willingness to stop, opinions about healthcare professionals who used to smoke) (questions 25-32)

5. Curriculum/training (i.e. formal training in smoking cessation techniques on the medical curriculum and knowledge about methods [pharmacological or counseling techniques] helping people to quit] (questions 33-41)

6. Demographics (age, gender, course year) (questions 42-44).

Our attention was focused in particular on questions about smoking behavior and intention to quit, attitudes 
regarding the role of healthcare professionals in smoking cessation, and training and knowledge about smoking cessation methods.

\section{Outcome measure}

In this survey, the outcome variable was "to be a current smoker," considering as "smokers" those who smoked cigarettes on at least 1 day during the 30 days before the survey.

\section{Statistical analysis}

Descriptive analyses were performed using frequencies, percentages and frequency tables for categorical variables. For the bivariate analysis chi-square tests were performed to evaluate differences for categorical variables. A binary logistic regression model was used to identify possible factors associated with tobacco smoking status. According to the Hosmer-Lemeshow procedure $^{27}$, only covariates having a $P$ value $<0.25$ at univariate analysis were introduced into the models. Moreover, gender and age were inserted into the regression model as possible confounding factors. The results are expressed as crude odds ratios (ORs) and adjusted ORs with 95\% confidence intervals (CIs), and the goodness of fit of the model was assessed by the Hosmer-Lemeshow test.

Statistical analysis was performed using the Statistical Package for the Social Sciences (SPSS) v. 19.0. The level of significance was set at $P \leq 0.05$.

\section{Results}

\section{Sample characteristics and prevalence of smoking}

The questionnaire was administered to 730 third-year medical students (response rate 100\%). Four hundred forty-four (60.8\%) were women, and 704 (96.4\%) were in the age range between 19 and 24 years. The prevalence of current smokers was 20.4\% (149/730) (Table 1).

Among the students of the sample, $64.1 \%$ had smoked a cigarette at some point in their life and $29.7 \%$ had smoked their first cigarette between 11 and 15 years. The highest rate of current smokers was found in the age range from 25 to 29 years $(43.8 \%)(P=0.064)$. There were more smokers among men than among women ( $22.4 \%$ vs $19.1 \%)$. Of the different cities, Salerno had the highest rate of smokers and Florence the lowest $(33.3 \%$ and $12.1 \%$, respectively; $P=0.09$ ) (Table 1 ).

\section{Attitudes, beliefs and knowledge}

Of the total sample (smokers and nonsmokers), 87.7\% believed that healthcare professionals should receive specific training in techniques to quit smoking, while $12.3 \%$ disagreed. More than half of the medical students believed that healthcare professionals should act as models for patients: $65 \%$ answered that healthcare pro-
Table 1 - Characteristics of the sample according to the outcome "being a current smoker"

\begin{tabular}{lccc}
\hline $\begin{array}{l}\text { Sociodemographic } \\
\text { variables }\end{array}$ & $\begin{array}{c}\text { Total } \\
\text { population } \\
\mathrm{N}\end{array}$ & $\begin{array}{c}\text { Current } \\
\text { smokers } \\
\mathrm{N}(\%)\end{array}$ & $P$ value \\
\hline & 730 & $149(20.4)$ & \\
Age (years) & 704 & $140(19.9)$ & $0.07 * * \wedge$ \\
$<25$ & 26 & $9(34.6)$ & \\
$\geq 25$ & & & $0.29 \wedge$ \\
Gender & 444 & $85(19.1)$ & \\
F & 286 & $64(22.4)$ & \\
M & & & \\
University & 73 & $12(16.4)$ & \\
Turin (North) & 133 & $23(17.3)$ & \\
Palermo (South) & 199 & $45(22.6)$ & \\
Padua (North) & 33 & $4(12.1)$ & \\
Florence (North) & 93 & $14(15.1)$ & \\
Brescia (North) & 42 & $12(28.6)$ & \\
Ferrara (North) & 50 & $14(28.0)$ & \\
Varese (North) & 42 & $14(33.3)$ & \\
Salerno (South) & 65 & $11(16.9)$ & \\
Udine (North) & & & \\
\hline
\end{tabular}

The level of significance was set at $P \leq 0.05$.

** Covariates having a $P$ value $<0.25$ at univariate analysis were introduced into the binary logistic regression models (Hosmer and Lemeshow ${ }^{27}$ ).

$\wedge$ Age and gender entered into the binary logistic regression models as confounding factors (although $P$ value was $<0.25$ ).

-Universities entered into the binary logistic regression models as dichotomous variables (macro areas: North and South).

fessionals have a role in giving advice or information about smoking cessation.

As regards the knowledge about smoking cessation methods, $90.4 \%$ of the sample stated they had received lessons on the risks associated with smoking during their university course, but $89.4 \%$ said not to have received any specific training on cessation techniques and around $9.5 \%$ did not know about the use of antidepressants (Table 2).

\section{Binary logistic regression}

We analyzed possible factors associated with smoking status. Multivariate analysis for the outcome "being a current smoker" showed that students from the southern Italian universities were significantly more likely to be smokers than students from northern Italian universities (OR = 2.05; 95\% CI: 1.05-4.00; adjusted OR = 2.0, 95\% CI: 1.03-3.97).

In addition, age $\geq 25$ years appeared to constitute a higher risk for being a smoker $(\mathrm{OR}=2.13$; 95\% CI: 0.934.89; adjusted OR $=2.21 ; 95 \% \mathrm{CI}$ : 0.96-5.08) and women had a lower probability of being smokers than men (OR $=0.82$; 95\% CI: 0.57-1.18; adjusted OR $=0.87,95 \%$ CI: $0.60-1.26)$. Students who believed that healthcare professionals had a role in giving advice or information about smoking cessation to patients appeared to have a lower probability of being smokers $(\mathrm{OR}=0.53$; $95 \% \mathrm{CI}$ : 
Table 2 - Outcome "smokers and non-smokers"

\begin{tabular}{|c|c|c|c|c|}
\hline Attitudes and beliefs & $\begin{array}{l}\text { Frequencies } \\
\quad \mathrm{N}(\%)\end{array}$ & Non-smokers & Current smokers & $P$ value \\
\hline \multicolumn{5}{|c|}{ Should HPs get specific training in cessation techniques? } \\
\hline yes & $640(87.7)$ & $80.3 \%$ & $19.7 \%$ & \multirow[t]{2}{*}{$0.2 * *$} \\
\hline no & $90(12.3)$ & $74.4 \%$ & $25.6 \%$ & \\
\hline \multicolumn{5}{|c|}{ Do HPs serve as role models for their patients and the public? } \\
\hline yes & $474(64.9)$ & $79.7 \%$ & $20.3 \%$ & \multirow[t]{2}{*}{0.86} \\
\hline no & $255(34.9)$ & $79.2 \%$ & $20.8 \%$ & \\
\hline \multicolumn{5}{|c|}{ Do HPs regularly advise smokers to quit? } \\
\hline yes & $649(95.1)$ & $79.4 \%$ & $20.6 \%$ & \multirow[t]{2}{*}{0.68} \\
\hline no & $34(4.7)$ & $82.4 \%$ & $17.6 \%$ & \\
\hline \multicolumn{5}{|c|}{ Do HPs regularly advise smokers to quit chewing/assuming tobacco? } \\
\hline yes & $680(93.2)$ & $79.9 \%$ & $20.1 \%$ & \multirow[t]{2}{*}{0.47} \\
\hline no & $49(6.7)$ & $75.5 \%$ & $24.5 \%$ & \\
\hline \multicolumn{5}{|c|}{$\begin{array}{l}\text { Do HPs have a role in giving advice or information about smoking } \\
\text { cessation to patients? }\end{array}$} \\
\hline yes & $688(94.4)$ & $80.2 \%$ & $19.8 \%$ & \multirow[t]{2}{*}{$0.07 * *$} \\
\hline no & $41(5.6)$ & $68.3 \%$ & $31.7 \%$ & \\
\hline \multicolumn{5}{|c|}{ Do patients have more chances to quit smoking if helped by HP? } \\
\hline yes & $576(79.2)$ & $79.7 \%$ & $20.3 \%$ & \multirow[t]{2}{*}{0.81} \\
\hline no & $151(20.8)$ & $78.8 \%$ & $21.2 \%$ & \\
\hline
\end{tabular}

HP, healthcare professional.

The level of significance was set at $P \leq 0.05$.

**Covariates having a $P$ value $<0.25$ at univariate analysis were introduced into the binary logistic regression models (Hosmer and Lemeshow ${ }^{27}$ ).

0.27-1.05; adjusted OR $=0.54 ; 95 \%$ CI: 0.27-1.07) than did those who believed that health professionals should receive specific training on cessation techniques $(\mathrm{OR}=$ 0.71, 95\% CI: 0.43-1.19; adjusted OR $=0.71$, 95\% CI: 0.421.20).

The Hosmer and Lemeshow goodness-of-fit test resulted in a value of $P=0.74$ (Table 3 ).

\section{Discussion}

This multicenter survey found a prevalence of $20.4 \%$ of smokers among Italian medical students. Additionally, the study provides important data on students' knowledge and attitudes related to tobacco use as well as tobacco cessation training based on standardized methods. Our results highlight the importance of focusing attention on smoking cessation training addressed to medical students. The majority of students believed in the role of healthcare professionals as models in society advising people to quit smoking, being aware that they might receive specific undergraduate training in counseling patients about smoking cessation ${ }^{28}$.

Students' knowledge about smoking cessation programs proved to be poor: in our survey $89.4 \%$ answered they had not received specific training in smoking cessation techniques and around 9.5\% did not know about the use of antidepressants. As regards the period in which such training could be given, there is no evidence of a superior effect in a specific period, but we must consider that medical students seem to be more conscious about the negative effects of tobacco smoking and tobacco-related diseases at the beginning of university courses ${ }^{29}$.

The smoking prevalence among healthcare providers remains high ${ }^{30}$ and a European survey found that the prevalence of smoking was higher among medical students than the general population ${ }^{31}$, while healthcare professionals could have great power in providing effective smoking prevention and cessation interventions in communities $^{11,12,32}$. Medical students, who represent the future medical practitioners, need to acquire specific skills in smoking cessation techniques that need to be introduced in the curricula of medical schools ${ }^{5,33}$.

Data from the Cross Countries GHPSS 2005-2009 study showed that in 19 of 40 sites, over $20 \%$ of the students were current smokers ${ }^{28}$, which is in perfect agreement with our findings.

In Europe and also in Italy, studies have been conducted on the knowledge, attitude and behaviors of students concerning tobacco smoking, but the methodology used was not based on standardized methods ${ }^{34-42}$.

\section{Limitations of the study}

Our study has some limitations concerning the study design and the self-reported data, which carry a risk of 


\begin{tabular}{|c|c|c|}
\hline Variables & $\begin{array}{l}\text { Crude OR } \\
(95 \% \mathrm{Cl})\end{array}$ & $\begin{array}{c}\text { Adjusted OR } \\
(95 \% \mathrm{Cl})\end{array}$ \\
\hline \multicolumn{3}{|l|}{ Age (years) } \\
\hline$<24$ (reference)* & 1 & 1 \\
\hline$\geq 25$ & $2.13(0.93-4.89)$ & $2.21(0.96-5.08)$ \\
\hline \multicolumn{3}{|c|}{$\begin{array}{l}* * \text { Should health professionals } \\
\text { get specific training in cessation } \\
\text { techniques? }\end{array}$} \\
\hline No (reference)* & 1 & 1 \\
\hline Yes & $0.71(0.43-1.19)$ & $0.71(0.42-1.20)$ \\
\hline \multicolumn{3}{|l|}{ Gender } \\
\hline Male (reference)* & 1 & 1 \\
\hline Female & $0.82(0.57-1.18)$ & $0.87(0.60-1.26)$ \\
\hline \multirow{3}{*}{\multicolumn{3}{|c|}{$\begin{array}{l}{ }^{* *} \text { Do health professionals } \\
\text { have a role in giving advice } \\
\text { or information about smoking } \\
\text { cessation to patients? }\end{array}$}} \\
\hline & & \\
\hline & & \\
\hline No (reference)* & 1 & 1 \\
\hline Yes & $0.53(0.27-1.05)$ & $0.54(0.27-1.07)$ \\
\hline \multicolumn{3}{|l|}{ Macro region } \\
\hline North (reference)* & 1 & 1 \\
\hline South & $2.03(1.05-4.00)$ & $2.00(1.03-3.97)$ \\
\hline
\end{tabular}

Hosmer and Lemeshow goodness-of-fit test: $P=0.74$

Dependent variable: "being a current smoker". Independent variables: Age, Gender, "Should health professionals get specific training in cessation techniques?", "Do health professionals have a role in giving advice or information about smoking cessation to patients?".

*Reference group.

**Hosmer-Lemeshow procedure (only covariates having a $P$ value $<0.25$ at univariate analysis were introduced into the models).

underreporting and recall bias, and this could have some concerns in the medical students' setting. However, the use of a standardized tool for data collection and the multicenter nature of this study made it possible to collect data from a large number of participants and to achieve high statistical power. Another possible limitation is that we have not taken into account all students belonging to the third-year course, but we have considered as our total sample only students who attended the class and, according to the GHPSS standard administration, we have not chosen the possibility to recover the absent ones. Another limitation is that the GHPSS investigated only third-year students, and there is a possibility that students receive cessation technique training during the later years of medical school. In order to verify this hypothesis, the GHPSS research coordinators found that, in the majority of countries, there is no formal training at any time ${ }^{28}$.

\section{Main finding of the study}

This survey revealed a percentage of $20.4 \%$ of current smokers among third-year medical students and showed that $89.4 \%$ of students never received any specific training in smoking cessation techniques during their medical courses. This should alert academic, medical and policy-making communities to the need to provide a complete curriculum to medical students, including training in smoking cessation techniques ${ }^{39}$.

\section{References}

1. World Health Organization (WHO): The MPOWER: A policy package to reverse the tobacco epidemic. World Health Organization Press, Geneva, Switzerland, 2008. Available at www.who.int/tobacco/mpower/mpower_english.pdf.

2. Osservatorio Fumo, Alcol e Droga (OssFAD): Relazione annuale sul tabagismo. Indagine DOXA [Annual report on tobacco use. The DOXA study]. Istituto Superiore di Sanità, Rome, 2010. Available at http://www.iss.it/fumo/rann/ cont.php?id=195\&lang=1\&tipo=3

3. Emmons KM: Smoking cessation and tobacco control: An overview. Chest, 116: 490S-492S, 1999.

4. Fiore MC, Jaén CR, Baker TB, Bailey WC, Benowitz NL, Curry SJ: Treating tobacco use and dependence: 2008 update. Clinical practice guideline. US Department of Health and Human Services, Public Health Service, Rockville, MD, 2008. Available at http://www.surgeongeneral.gov/tobacco/treating_tobacco_use08.pdf

5. Chatkin J, Chatkin G: Learning about smoking during medical school: Are we still missing opportunities? Int J Tuberc Lung Dis, 13: 429-437, 2009.

6. Ferry LH, Grissino LM, Runfola PS: Tobacco dependence curricula in US under graduate medical education. JAMA, 282: 825-829, 1999.

7. Springer CM, Tannert Niang KM, Matte TD, Miller N, Bassett MT, Frieden TR: Do medical students know enough about smoking to help their future patients? Assessment of New York City fourth-year medical students' knowledge of tobacco cessation and treatment for nicotine addiction. Acad Med, 83: 982-989, 2008.

8. Tønnessen P, Carrozzi L, Fagerström KO, Gratziou C, Jimenez-Ruiz C, Nardini S: Smoking cessation in patients with respiratory disease: a high priority, integral component of therapy. Eur Respir J, 29: 390-417, 2007.

9. La Torre G, Sandström P, Falkenberg M, Tanskanen P, Patja $\mathrm{K}$, Kauhanen J: Smoking prevention and smoking cessation training in European medical schools. Eur J Public Health, 19 (Suppl 1): 42, 2009.

10. La Torre G, Thuemmler K, Bes-Rastrollo M, Czaplicki M, Siliquini R, Firenze A: Tobacco smoking and medical students: results of a multicentre Global Health Professions Survey in Europe. Eur J Public Health, 19 (Suppl 1): 41-42, 2009.

11. Richmond RL, Kehoe L: Smoking behavior and attitudes among Australian medical students. Med Educ, 31: 169176, 1997.

12. Braun B, Jinnet B, Fowles J, Solberg LI, Kind EA, Lando H, Pine D: Smoking-related attitudes and clinical practices of medical personnel in Minnesota. Am J Prev Med, 27: 316322, 2004.

13. Slater P, McElwee G, Fleming P, McKenna H: Nurses' smoking behaviour related to cessation practice. Nurs Times, 102: 32-37, 2006.

14. Gallus S, Muttarak R, Franchi M, Pacifici R, Colombo P, Boffetta P, Leon ME, La Vecchia C: Why do smokers quit? Eur J Cancer Prev, 22: 96-101, 2013.

15. Ferketich AK, Gallus S, Colombo P, Fossati R, Apolone G, Zuccaro P, La Vecchia C: Physician-delivered advice to quit smoking among Italian smokers. Am J Prev Med, 35: 60-63, 2008. 
16. Ferketich AK, Khan Y, Wewers ME: Are physicians asking about tobacco use and assisting with cessation? Results from the 2001-2004 National Ambulatory Medical Care Survey (NAMCS). Prev Med, 43: 472-476, 2006.

17. Rosen C, Ashley M: Smoking and the health professional: recognition and performance of roles. Can J Public Health, 69: 399-406, 1979.

18. Mackay J, Eriksen M: The tobacco Atlas, p 24, Myriad Editions Limited, Brighton, 2002.

19. Dawley HH Jr, Cartel SF, Morrison JE: The discouragement of smoking in a hospital setting: the importance of modeled behavior. Int J Addict, 16: 905-910, 1981.

20. Zwar NA, Richmond RL: Role of the general practitioner in smoking cessation. Drug Alcohol Rev, 25: 21-26, 2006.

21. La Torre G, Sandström P, Falkenberg M, Tanskanen P, Patja $\mathrm{K}$, Kauhanen J: Activities in the prevention and control of tobacco smoking among schools of medicine in some countries of the European region. Eur J Public Health, (Suppl 1): 42, 2009.

22. Soeken KL, Bausell RB, Winklestein M, Carson VJ: Preventive behaviour: attitudes and compliance of nursing students. J Adv Nurs, 14: 1026-1033, 1989.

23. Spencer J: Nurses' cigarette smoking in England and Wales. Int J Nurs Stud, 21: 69-79, 1984.

24. La Torre G, Saulle R, Di Nardo F, Germani T: Smoking cessation interventions in nurses and other health care workers. Reviews in Health Care, 2: 95-105, 2011.

25. Warren CW, Jones NR, Chauvin J, Peruga A, GTSS Collaborative Group: Tobacco use and cessation counselling: cross-country. Data from the Global Health Professions Student Survey (GHPSS), 2005-7. Tob Control, 17: 238-247, 2008.

26. Gualano MR, Bontempi C, Saulle R, Ricciardi W, La Torre G: Validation of the Global Health Professions Students Survey questionnaire in Italy. Ital J Public Health, 8: 392-398, 2011.

27. Hosmer DW, Lemeshow S: Applied logistic regression. John Wiley \& Sons, New York, 1989.

28. Warren CW, Sinha DN, Lee J, Lea V, Jones NR: Tobacco use, exposure to secondhand smoke, and training on cessation counseling among nursing students: cross-country data from the Global Health Professions Student Survey (GHPSS), 2005-2009. Int J Environ Res Public Health, 6: 25342549, 2009.

29. Lucenteforte E, Vannacci A, Cipollini F, Gori A, Santini L, Franchi G, Terrone R, Ravaldi C, Mugelli A, Gensini GF, Lapi F: Smoking habits among university students in Florence: is a medical degree course the right choice? Prev Med, 51: 429-430, 2010.

30. Ficarra MG, Gualano MR, Capizzi S, Siliquini R, Liguori G, Manzoli L, Briziarelli L, Parlato A, Cuccurullo P, Bucci R, Pi- at SC, Masanotti G, de Waure C, Ricciardi W, La Torre G: Tobacco use prevalence, knowledge and attitudes among Italian hospital health care professionals. Eur J Public Health, 21: 29-34, 2011.

31. La Torre G, Kirch W, Bes-Rastrollo M, Ramos RM, Czaplicki M, Gualano MR, Thümmler K, Ricciardi W, Boccia A; GHPSS Collaborative Group: Tobacco use among medical students in Europe: results of a multicentre study using the Global Health Professions Student Survey. Public Health, 126: 159-164, 2011

32. Saulle R, La Torre G: Baccus, Tobacco and Venus: old and new challenges for public health. Ital J Public Health, 7: 101-105, 2010.

33. Ferrante M, Fiore M, Leon L, Costantidines F, Castaing M, Fallico R, Sciacca S, Modonutti G: Age of smoking initiation, tobacco habits and risk perception among primary, middle and high school students in south Italy. Ital J Public Health, 7: 262-267, 2010.

34. Melani AS, Verponziani W, Boccoli E, Trianni GL, Federici A, Amerini R, Vichi MG, Sestini P: Tobacco smoking habits, attitudes and beliefs among nurse and medical students in Tuscany. Eur J Epidemiol, 16: 607-611, 2000.

35. Heras Tébar A, García Sanchón C, Hernández López MC, Ballestín N, Nebot M: Smoking among nursing students in Catalonia: knowledge, attitudes and practice. Gac Sanit, 11: 267-273, 1997.

36. Dekker HM, Looman CW, Adriaanse HP, van der Maas PJ: Prevalence of smoking in physicians and medical students, and the generation effect in The Netherlands. Soc Sci Med, 36: 817-822, 1993.

37. Waalkens HJ, Cohen Schotanus J, Adriaanse H, Knol K: Smoking habits in medical students and physicians in Groningen, The Netherlands. Eur Respir J, 5: 49-52, 1992.

38. Clareboets S, Sivarajasingam V, Chestnutt IG: Smoking cessation advice: knowledge, attitude and practice among clinical dental students. Br Dent J, 208: 173-177, 2010.

39. Tirodimos I, Georgouvia I, Savvala TN, Karanika E, Noukari D: Healthy lifestyle habits among Greek university students: differences by sex and faculty of study. East Mediterr Health J, 15: 722-728, 2009.

40. Raupach T, Shahab L, Baetzing S, Hoffmann B, Hasenfuss G, West R, Andreas S: Medical students lack basic knowledge about smoking: findings from two European medical schools. Nicotine Tob Res, 11: 92-98, 2009.

41. Borges A, Marques F, Lima J, Costa L, Gonçalves P, Fernandes R, Gonçalves N: Smoking habits of sixth year medical students and anti-smoking measures in Portugal. Rev Port Pneumol, 14: 379-390, 2008.

42. Smith DR, Leggat PA: An international review of tobacco smoking among medical students. J Postgrad Med, 53: 5562, 2007. 